Robert J. Foster

\title{
The Significance of Exemplars for the Interpretation of the Letter of James
}

[Die Bedeutsamkeit von Vorbildern für die Deutung des Jakobusbriefs.]

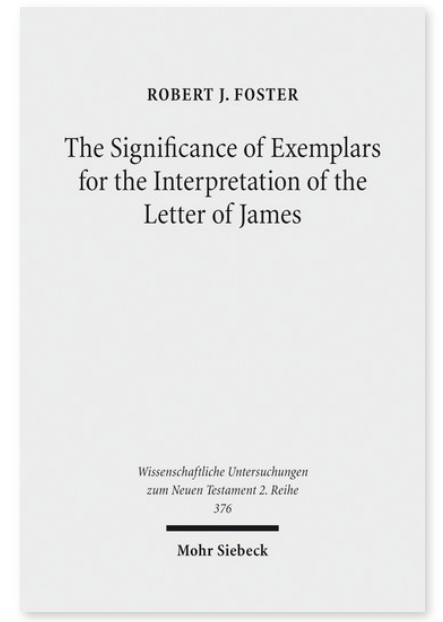

2014. X, 233 Seiten. WUNT II 376

ISBN 978-3-16-153295-5

DOI 10.1628/978-3-16-153295-5

eBook PDF 94,00€

ISBN 978-3-16-153263-4

fadengeheftete Broschur 94,00€
Veröffentlicht auf Englisch.

Robert J. Foster untersucht in diesem Buch, wie Jakobus seine vier Figuren aus der jüdischen Geschichte und Tradition (Abraham, Rahab, Hiob und Elija) einsetzt, und analysiert dabei sowohl ihre gemeinsame als auch ihre individuelle Funktion im Text. Dabei kommt er zu dem Ergebnis, dass jedes dieser vier Vorbilder bis an seine Grenzen geprüft wurde (wenngleich auf sehr unterschiedliche Art und Weise), aber Gott dennoch vollkommen ergeben geblieben ist. Durch diese Hingabe wurde jedes dieser Vorbilder zum Außenseiter, sowohl im kulturellen als auch im historischen Kontext. »jakobus « drängt seine Leserschaft, in ihren weniger extremen alltäglichen Prüfungen diesen Vorbildern nachzueifern, indem sie weltliche Wertvorstellungen in der Welt ablehnt und nach der neu interpretierten Tora von Jesus Christus lebt.

Robert J. Foster Born 1951; had a career in banking before commencing his theological studies; 2012 PhD from the University of Birmingham.

Jetzt bestellen:

https://mohrsiebeck.com/buch/the-significance-of-exemplars-for-the-interpretation-of-the-letter-of-james-9783161532955? no_cache=1

order@mohrsiebeck.com

Telefon: +49 (0)7071-923-17

Telefax: +49(0)7071-51104 